\title{
Avaliação da Sobrevivência e do Desenvolvimento de Mudas de Capim Vetiver (Vetiveria zizanioides) em Raízes Nuas e Produzidas em Saquinhos de Polietileno Plantadas em Diferentes Espaçamentos
}

Leandro Luiz de Andrade - Tecnólogo em Gestão Ambiental pelo IFSULDEMINAS Campus Inconfidentes, Praça Tiradentes, 416, centro, Inconfidentes/MG. CEP: 37576-000 - leandroluizcapi@yahoo.com.br, Lilian Vilela de

Andrade Pinto - Prof. ${ }^{a}$ DSc. no IFSULDEMINAS Campus Inconfidentes, Praça Tiradentes, 416, centro, Inconfidentes/MG. CEP: 37576-000 - lilianvap@gmail.com, Michender Werison Motta Pereira - Pós-Graduando em Gestão Ambiental no IFSULDEMINAS Campus Inconfidentes, Praça Tiradentes, 416, centro, Inconfidentes/

MG. CEP: 37576-000 - michender.ambiental@gmail.com, Rafael Xavier Souza - Graduando Tecnologia em Gestão Ambiental no IFSULDEMINAS Campus Inconfidentes, Praça Tiradentes, 416, centro, Inconfidentes/MG. CEP: 37576-000, rafael.ifsm@gmail.com

\section{RESUMO}

A utilização de plantas para estabilização de solos caracteriza-se como uma técnica de baixo custo quando comparado com as grandes obras de bioengenharia. Desta forma, o capim vetiver (Vetiveria zizanioides) apresenta-se como uma boa opção de planta pioneira na reabilitação e estabilização de solos pois possui uma enorme capacidade de sobreviver à secas prolongadas uma vez que suas raízes atingem uma enorme profundidade (até $3 \mathrm{~m}$ ), Ihe proporcionando retirar água do solo mesmo nas épocas de estiagem. Além disso, apresentam grande capacidade na estabilização de solos sujeitos a processos erosivos e com déficit nutricional, aumentando o poder de agregação do solo. Neste sentido o objetivo do presente trabalho foi avaliar a sobrevivência e desenvolvimento de mudas de capim vetiver ( $V$. zizanioides) em raízes nuas e produzidas em saquinhos de polietileno plantadas em diferentes espaçamentos, visando-se futuros projetos de proteção de encostas com esta gramínea. O experimento foi realizado na fazenda escola do IFSULDEMINAS - campus Inconfidentes, MG, em uma encosta experimental, com declividade média de $30^{\circ}$ e rampa de $6 \mathrm{~m}$. Foram avaliados 2 tipos de mudas de capim vetiver (raízes nuas e produzidas em saquinhos de polietileno) e 9 diferentes espaçamentos. Os parâmetros mensurados foram a taxa de sobrevivência das mudas 60 dias após o plantio; altura e diâmetro ao nível do solo das plantas no período de 150 à 270 dias após o plantio. Concluiu-se que: i) a taxa de sobrevivência, o diâmetro ao nível do solo e a altura das plantas de vetiver não é influenciada pelo espaçamento de plantio; ii) as plantas provenientes de mudas de vetiver produzidas em saquinhos de polietileno apresentam taxa de sobrevivência e diâmetro ao nível do solo superior àquelas plantadas diretamente no campo (raízes nuas); e iii) mudas produzidas em raízes nuas inicialmente apresentam menores valores de altura, entretanto após certo período de tempo estas mudas atingem valores similares ou maiores que os apresentados por mudas produzidas em saquinhos de polietileno.

Palavras-Chave: Proteção de encostas, diâmetro ao nível do solo, taxa de sobrevivência, altura de plantas, produção de mudas.

\section{Evaluation of Survival and Development of Seedlings of Vetiver Grass (Vetiveria zizanioides) in Bare Rooted and Grown in Polyethylene Bags Planted at Different Spacings}

\section{ABSTRACT}

The use of plants for soil stabilization is characterized as a low cost technique compared to the great works of bioengineering. Thus, the vetiver grass shows itself as a good choice of pioneer plant in the rehabilitation and soil stabilization, as it has a great capacity to survive prolonged drought because its roots reach an enormous depth of $3 \mathrm{~m}$ permiting it to remove water from ground even in times of drought, besides they have a high capacity to stabilize soil erosion or suffering nutritional deficits, increasing the power of soil aggregation. In this sense the purpose of this study is to evaluate the survival and development of seedlings of vetiver grass (Vetiveria zizanioides) in bare root and grown in polyethylene bags planted at different spacings, aiming future projects to protect the slopes with this grass. The experiment was conducted at the school IFSULDEMINAS - campus Inconfidentes/MG/Brazil in an experimental slope of 30 degrees and ramp of $6 \mathrm{~m}$. It was planted two types of seedlings of vetiver grass (bare rooted and grown in polyethylene bags) and 9 different spacings. The measured parameters were the survival rate of seedlings 60 days after planting, height and diameter at ground level of the plants in the period of 150 to 270 days after planting. It was concluded that: i) the survival rate, diameter at ground level and plant height of vetiver is not 
influenced by plant spacing. ii) the plants from seedlings of vetiver grown in polyethylene bags have survival rate and diameter at ground level higher than those planted directly in the field (bare root) and iii) seedlings grown in bare root initially have lower values of height, however after a certain period of time these seedlings reach similar or higher values than those submitted by seedlings grown in polythene bags.

Keywords: Protection of slopes, diameter at ground level, survival rate, plant height, seedling production.

\section{INTRODUÇÃO}

O solo, substrato básico a sobrevivência das plantas suporta sobre sua superfície os mais diversos usos para satisfazer as necessidades humanas de obter fonte para seu sustento e sobrevivência. Os usos do solo trazem alterações drásticas em suas características físicas decorrentes da exposição do mesmo as águas de precipitação que originam as erosões (Bertoni \& Lom-bardi Neto, 1990).

A erosão hídrica, em sua maioria, é o resultado das águas que escoam sobre as encostas, causando o arraste de partículas de solo e material orgânico para regiões mais baixas da paisagem/encosta. A encosta quando desprotegida, apresentando superfície nua, sem estrutura que contenha a força das águas fica propicia ao processo de erosão. Com o início do processo erosivo a desestabilização do solo aumenta pois a derivação do solo leva consigo não apenas material superficial, carregando também grande parte da matéria orgânica integrante deste solo (Bertoni \& Lombardi Neto, 1990).

Moreira (2006) destaca que a degradação é um processo induzido pelo homem ou por acidente natural que diminui a atual e futura capacidade produtiva do ecossistema.

Segundo Castro (2007), a principal forma de degradação do solo constitui-se do processo erosivo. Caputi (1997) destaca que no mundo inteiro a perda de solos cultivados em decorrência do arraste de partículas por águas provenientes de precipitações representa miIhões de toneladas por ano. Isso provoca o empobrecimento dos terrenos cultivados, tornando-os cada vez mais improdutivos, numa época em que a população mundial aumenta significativamente, e a demanda por alimentos, conseqüentemente, também aumenta (Pereira, 2006).

Além dos prejuízos econômico-ambientais, os processos erosivos podem afetar diretamente a sociedade. Grandes cidades sofrem com o mau planejamento que amplia as possibilidades de crescimento descontrolado, normalmente dando margem para que a cidade cresça em direção as encostas. $O$ fato real de que cidades são fundadas ao pé de encostas traz diversas conseqüências, pois com o início das chuvas as áreas de encostas ficam instáveis a tal ponto que ocasionam deslizamentos que levam até a margem dos rios tudo que está à sua frente, casas, carros quando não vidas.

A utilização de plantas para estabilização de solos caracteriza-se como uma técnica de baixo custo quando comparado com as grandes obras de bioengenharia (Martinho, 2005).

Desta forma, o capim vetiver apresenta-se como uma boa opção de planta pioneira na reabilitação e estabilização de solos, pois possuí uma enorme capacidade de sobreviver à secas prolongadas uma vez que suas raízes atingem uma enorme profundidade the proporcionando retirar água do solo mesmo nas épocas de estiagem, alem de apresentarem grande capacidade em estabilizar solos sujeitos ou sofrendo processos erosivos e com déficit nutricional aumentando o poder de agregação do solo (Castro, 2007).

O vetiver é usado na conservação de solos agrícolas, estabilização de locais inclinados, reabilitação de solos salinos e contaminados, como barreira efetiva para controle de erosão e sedimentos (Truong \& Hart, 2001).

Segundo Pereira (2006), o capim vetiver apresenta rápido crescimento em altura e diâmetro. Este bom crescimento se deve principalmente a capacidade da planta em aproveitar melhor o nitrogênio incorporado ao solo.

O vetiver se adapta às mais diversas e inóspitas condições edafoclimáticas, assim sendo se desenvolve onde nenhuma outra planta sobreviveria (Truong, 2000). Extremamente rústica, o vetiver é simultaneamente hidrófilo e xerófilo, além de resistir a extremos hídricos (300-3.000 mm/ano), também tolera extremos térmicos $\left(-14^{\circ} \mathrm{C} \mathrm{a}+55^{\circ} \mathrm{C}\right)$. O vetiver vegeta em praticamente qualquer tipo de terreno, tolerando solos de baixa fertilidade, e com valores extremos de $\mathrm{pH}$ (3-10), salinidade e toxidez. Caso venha a ser enterrado, pelo deslocamento e o acumulo de sedimentos, os nós do capim vetiver emitem novas raízes, que nivelam a planta com a nova superfície do terreno.

Neste sentido o objetivo do presente trabalho foi avaliar a sobrevivência e o desenvolvimento de mudas de capim vetiver ( $V$. zizanioides) em raízes nuas e produzidas em saquinhos de polietileno plantadas em diferentes espaçamentos, visando-se futuros projetos de proteção de encostas com esta gramínea.

\section{MATERIAIS E MÉTODOS}

\section{Caracterização da área}

O experimento foi instalado em uma encosta experimental com declividade média de $30^{\circ}$ e rampa de $6 \mathrm{~m}$. As mudas de capim vetiver ( $V$. zizanioides) foram plantadas em 9 espaçamentos conforme demonstra a tabela 1. 
Tabela 1. Espaçamentos de plantio utilizados no experimento

\begin{tabular}{|c|c|c|}
\hline \hline Espaçamentos & Entre Linhas $(\mathbf{m})$ & Entre plantas $(\mathbf{m})$ \\
\hline \hline $1 \times 0,15$ & 1 & 0,15 \\
\hline $1 \times 0,30$ & 1 & 0,30 \\
\hline $1 \times 0,45$ & 1 & 0,45 \\
\hline $1,5 \times 0,15$ & 1,5 & 0,15 \\
\hline $1,5 \times 0,30$ & 1,5 & 0,30 \\
\hline $1,5 \times 0,45$ & 1,5 & 0,45 \\
\hline $2 \times 0,15$ & 2 & 0,15 \\
\hline $2 \times 0,30$ & 2 & 0,30 \\
\hline $2 \times 0,45$ & 2 & 0,45 \\
\hline
\end{tabular}

O município de Inconfidentes localiza-se no sul do estado de Minas Gerais e apresenta altitude média de $855 \mathrm{~m}$ e posição geográfica de latitude S $22^{\circ} 19^{\prime \prime} 00^{\prime} \mathrm{e}$ longitude W $46^{\circ} 19^{\prime \prime} 40^{\prime}$. O clima da região, segundo a classificação de KOËPPEN é do tipo tropical úmido $(\mathrm{CWb})$, com duas estações definidas: chuvosa (outubro a março) e seca (abril a setembro), com médias anuais de $1.800 \mathrm{~mm}$ e $19^{\circ} \mathrm{C}$ de precipitação e temperatura, respectivamente. foram:

\section{Os parâmetros mensurados no experimento}

i) taxa de sobrevivência das mudas, sendo determinada com base no número de mudas existentes na área 60 dias após o plantio em relação ao número de mudas plantadas.

ii) altura das plantas a cada 30 dias (Figura 1A).

iii) diâmetro ao nível do solo das plantas a cada 30 dias (Figura 1B).

Os parâmetros altura e diâmetro das plantas foram determinados no período de 150 a 270 dias após o plantio, com auxilio de fita métrica e paquímetro digital, respectivamente, totalizando 5 medições.

Todos os parâmetros mensurados foram avaliados em função do espaçamento de plantio e do tipo de muda utilizada.

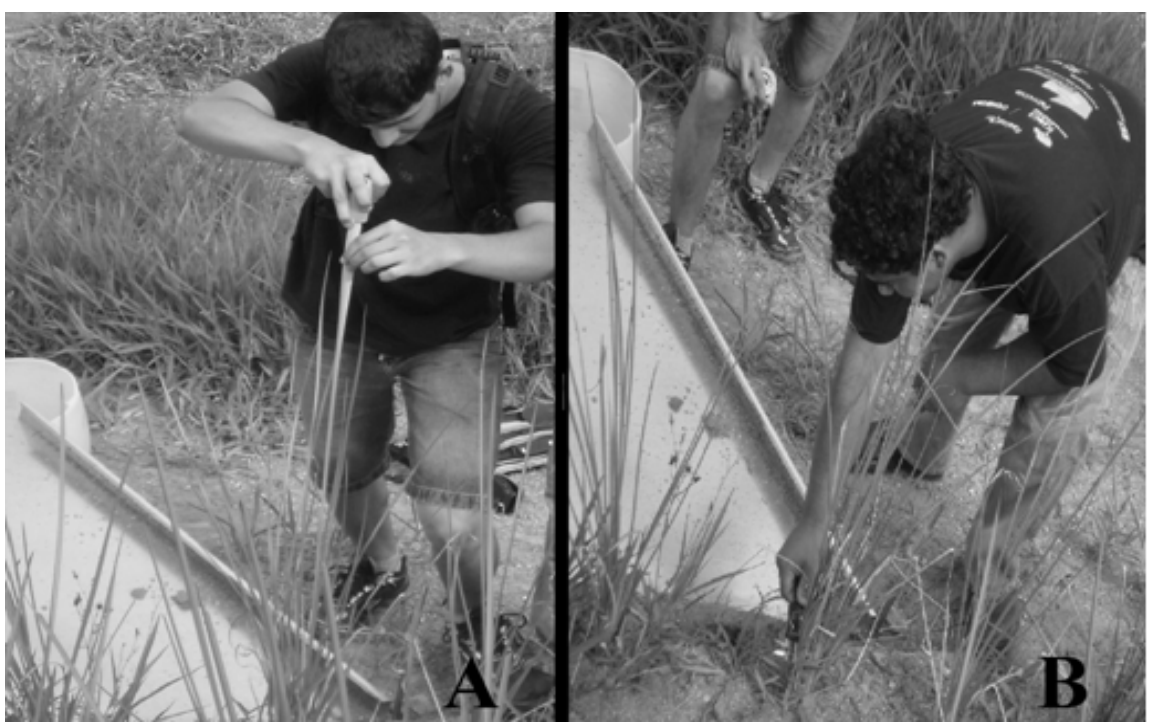

Figura 1. A) Avaliação da altura das plantas de vetiver, com fita métrica. B) Avaliação do diâmetro ao nível do solo das plantas de vetiver com auxílio de paquímetro digital.

\section{Experimento 1 plantio}

Para avaliar o efeito do espaçamento de plantio em plantas de capim vetiver foi utilizado o delineamento experimental em blocos casualizados, sendo 9 tratamentos (espaçamentos, conforme tabela 1) e 3 blocos/ repetições.

A área de cada parcela é de $15 \mathrm{~m} 2$, sendo $2,5 \mathrm{~m}$ de largura por $6 \mathrm{~m}$ de comprimento. Para controlar o efeito dos diferentes tratamentos deixou-se uma bordadura com plantas de $0,5 \mathrm{~m}$ nas laterais de cada parcela,totalizando uma área útil de 9 m2(Figura 2). 


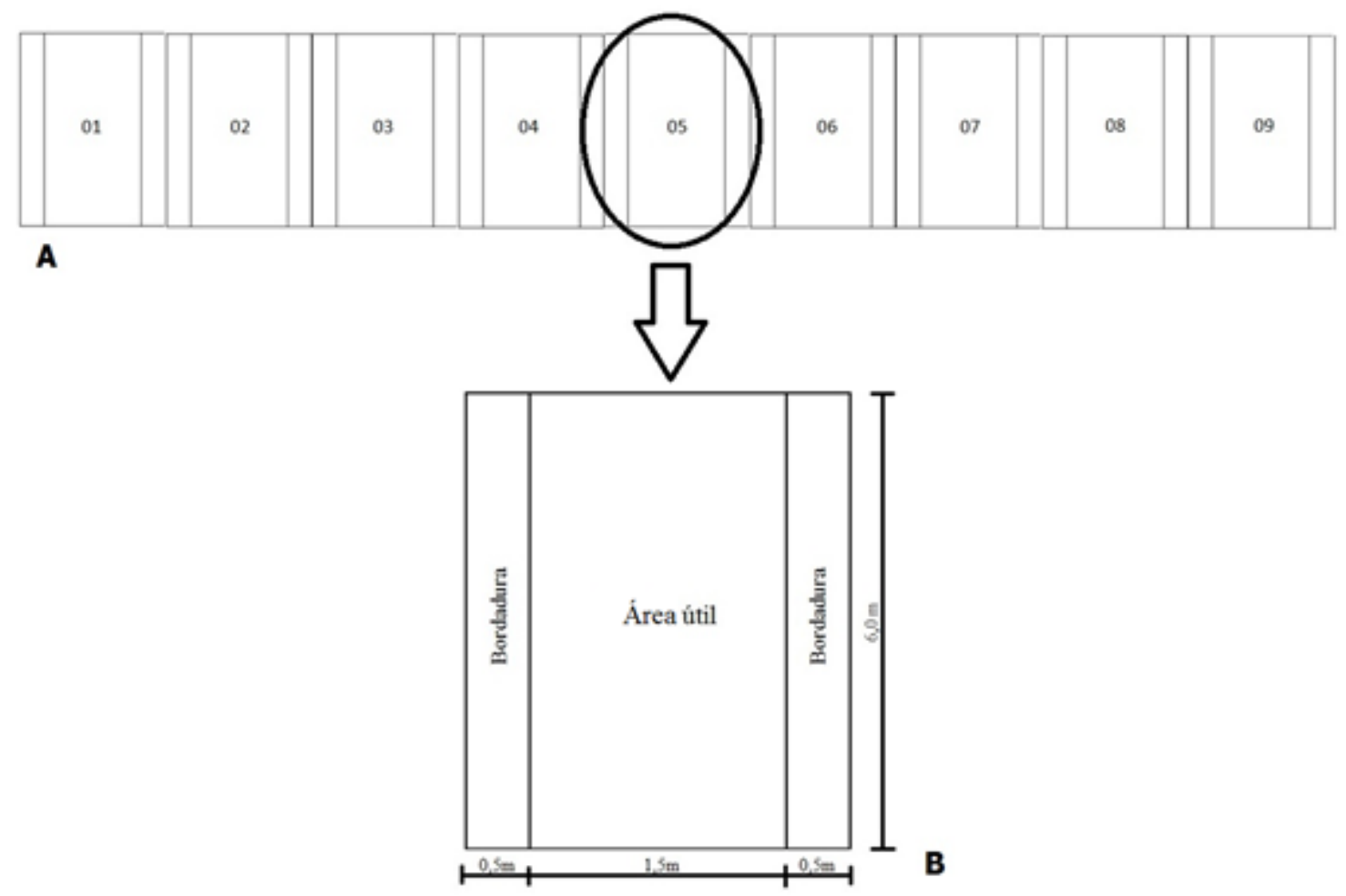

Figura 2. Croqui de um bloco do experimento: A) Bloco com as 9 parcelas dos diferentes espaçamentos. B) Parcela de $15 \mathrm{~m} 2$, bordadura de $0,5 \mathrm{~m}$ nas laterais da parcela e área útil de $9 \mathrm{~m} 2$.

\section{Experimento 2 - Efeito do tipo de muda}

Para avaliar o efeito do tipo de muda foram utilizados dois tratamentos, sendo mudas em raízes nuas e mudas produzidas em saquinhos de polietileno (Figura 3), com 320 repetições (plantas).
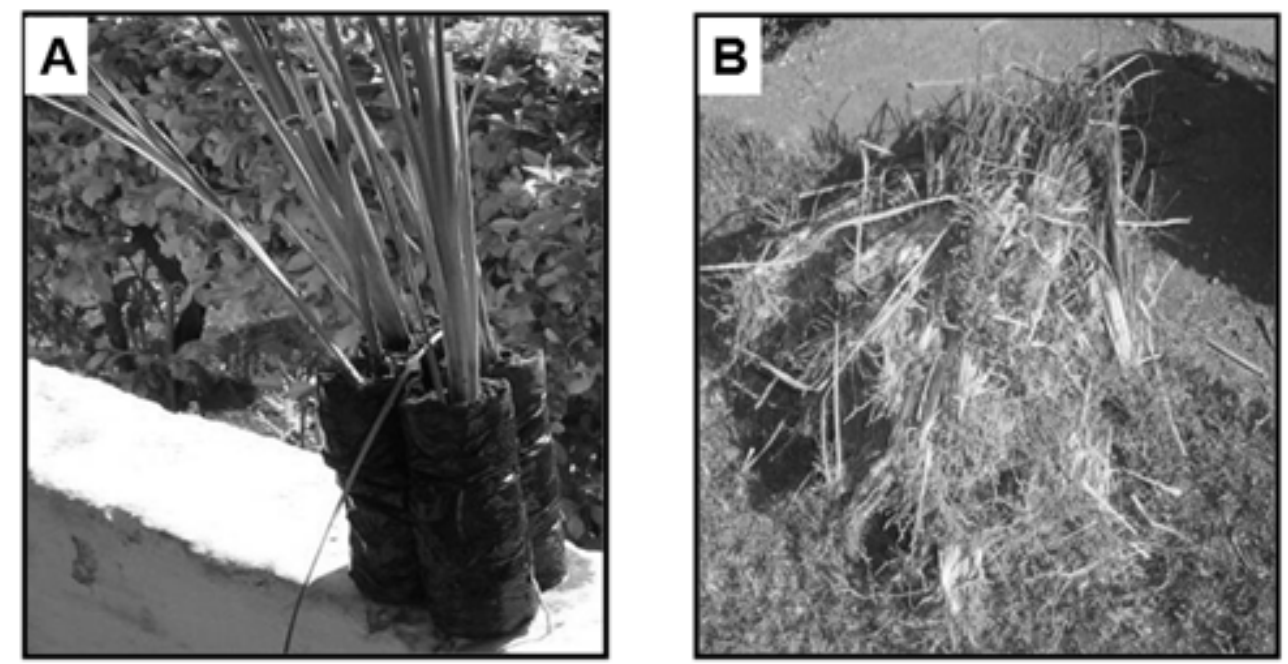

Figura 3. Mudas de vetiver: A) Produzidas em saquinhos de polietileno. B) Produzidas em raízes nuas.

As mudas de saquinhos foram selecionadas e padronizadas a partir de matrizes de qualidade, fazendo-se o uso de substrato composto por esterco bovino previamente curtido e terra de barranco. As mudas ficaram no viveiro de mudas do IFSULDEMINAS - Campus
Inconfidentes por 90 dias e em seguida foram plantadas na encosta experimental. Já as mudas em raízes nuas foram desmembradas de matrizes de qualidade e plantadas diretamente na encosta experimental (Figura 4). 


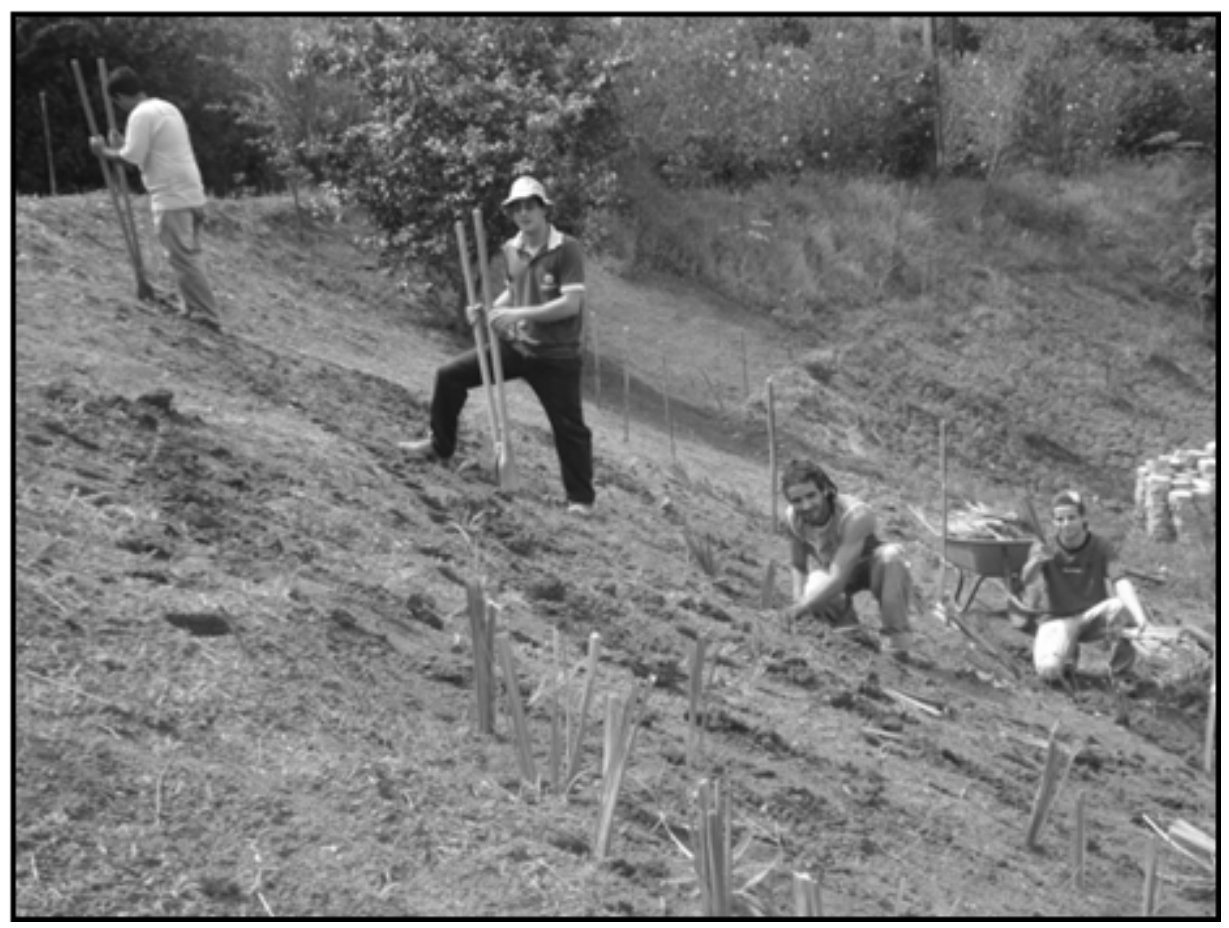

Figura 4. Plantio das mudas na encosta experimental, Inconfidentes/MG.

\section{Análise estatística}

A análise dos dados dos parâmetros mensurados foi realizada por meio da análise de variância (ANOVA) e as médias dos dados foram comparadas pelo teste de Tukey, ao nível de $5 \%$ significância, usando-se o programa SISVAR 4.3 (Ferreira, 2000).

\section{RESULTADOS E DISCUSÃO}

\section{Experimento 1 - Efeito do espaçamento de plantio}

\section{Taxa de sobrevivência}

Os diferentes espaçamentos de plantio estudados não apresentaram influência significativa na taxa sobrevivência das mudas de vetiver, conforme demonstrado pela tabela 2 .

Tabela 2. Taxa de sobrevivência de mudas de vetiver sob diferentes espaçamentos, Inconfidentes/MG.

\begin{tabular}{|c|c|}
\hline Espaçamento $(\mathrm{m})$ & Taxa de sobrevivência (\%) \\
\hline \hline $2 \times 0,45$ & $85,72 \mathrm{a}$ \\
\hline $2 \times 0,30$ & $89,81 \mathrm{a}$ \\
\hline $1,5 \times 0,15$ & $91,48 \mathrm{a}$ \\
\hline $1,5 \times 0,30$ & $93,33 \mathrm{a}$ \\
\hline $1 \times 0,45$ & $93,88 \mathrm{a}$ \\
\hline $1,5 \times 0,45$ & $94,29 \mathrm{a}$ \\
\hline $1 \times 0,30$ & $94,71 \mathrm{a}$ \\
\hline $1 \times 0,15$ & $95,23 \mathrm{a}$ \\
\hline $2 \times 0,15$ & $96,76 \mathrm{a}$ \\
\hline $\mathrm{CV}$ & $5,29 \%$ \\
\hline
\end{tabular}

Médias seguidas pela mesma letra na coluna não diferem estatisticamente entre si, pelo teste de Tukey $(P<0,05)$.

\section{Altura das plantas}

A altura das plantas de capim vetiver não apresentou diferença significativa em função do espaçamento de plantio ( Tabela 3 ). Isso se deve ao fato de que as plantas de vetiver por conter um sistema radicular muito profundo, que segundo Pereira (2006) pode alcançar 3 metros de profundidade, não competem entre si mesmo em diferentes espaçamentos. 
Tabela 3. Altura, em metros, das plantas de capim vetiver, dos 150 aos 270 dias após o plantio em diferentes espaçamentos, Inconfidentes/MG.

\begin{tabular}{|c|c|c|c|c|c|c|}
\hline \multirow{2}{*}{$\begin{array}{c}\text { Espaçamen- } \\
\text { to }(\mathrm{m})\end{array}$} & \multicolumn{5}{|c|}{ Idade (dias) } & \multirow{2}{*}{$\begin{array}{c}\text { Crescimen- } \\
\text { to no Perío- } \\
\text { do }(\mathrm{m}) \\
\end{array}$} \\
\hline & 150 & 180 & 210 & 240 & 270 & \\
\hline $1 \times 0,15$ & $0,66 a$ & $0,76 a$ & $0,92 \mathrm{a}$ & $1,25 \mathrm{a}$ & $1,32 \mathrm{a}$ & 0,66 a \\
\hline $1 \times 0,30$ & $0,62 a$ & $0,85 a$ & $0,96 a$ & $1,26 a$ & $1,36 \mathrm{a}$ & $0,74 \quad a$ \\
\hline $1 \times 0,45$ & $0,52 \mathrm{a}$ & $0,65 a$ & $0,79 a$ & $1,00 \mathrm{a}$ & 1,15 & 0,63 a \\
\hline $1,5 \times 0,15$ & $0,67 a$ & $0,80 \mathrm{a}$ & $0,86 a$ & $1,06 \mathrm{a}$ & 1,25 & $0,58 \quad a$ \\
\hline $1,5 \times 0,30$ & $0,70 a$ & $0,89 a$ & $0,94 \mathrm{a}$ & $1,15 a$ & 1,22 & 0,52 a \\
\hline $1,5 \times 0,45$ & $0,69 a$ & $0,83 a$ & $0,94 a$ & $1,18 \mathrm{a}$ & 1,27 & 0,58 a \\
\hline $2 \times 0,15$ & $0,63 a$ & $0,81 \mathrm{a}$ & $0,88 a$ & $1,08 \mathrm{a}$ & 1,19 & 0,56 a \\
\hline $2 \times 0,30$ & $0,48 a$ & $0,61 \mathrm{a}$ & $0,78 a$ & $1,04 \mathrm{a}$ & 1,18 & 0,70 a \\
\hline $2 \times 0,45$ & $0,53 a$ & $0,65 a$ & $0,80 a$ & $0,97 a$ & 1,12 & 0,59 a \\
\hline CV (\%) & 17,19 & 14,63 & 10,34 & 16,90 & 14,27 & 13,34 \\
\hline
\end{tabular}

Médias seguidas pela mesma letra na coluna não diferem estatisticamente entre si, pelo teste de Tukey $(P<0,05)$.

\section{Diâmetro das plantas}

O diâmetro ao nível do solo das plantas em função do espaçamento de plantio não apresentou diferença estatística para nenhum dos espaçamentos testados. Destaca-se que todos os espaçamentos testados apresentaram crescimento similar (Figura 5).

Estes resultados são importantes do ponto de vista de proteção do solo pelas plantas. Conforme descrito por Truong \& Hart (2001), quanto maior diâmetro ao nível do solo maior a capacidade de retenção de sedimentos da planta.
Estes resultados demonstram que o plantio de vetiver em encostas inclinadas pode ser efetuado levando-se em consideração as necessidades do projeto, ou seja, em caso de necessidade de cobertura do solo mais rápida, deverão ser utilizados espaçamentos menores, e caso a necessidade seja por um menor custo de proteção, poderão ser utilizados espaçamentos de plantio maiores, que empregam menos mudas, insumos e mão de obra. Desta forma, em ambas as situações o diâmetro ao nível do solo das plantas terá comportamento similar.

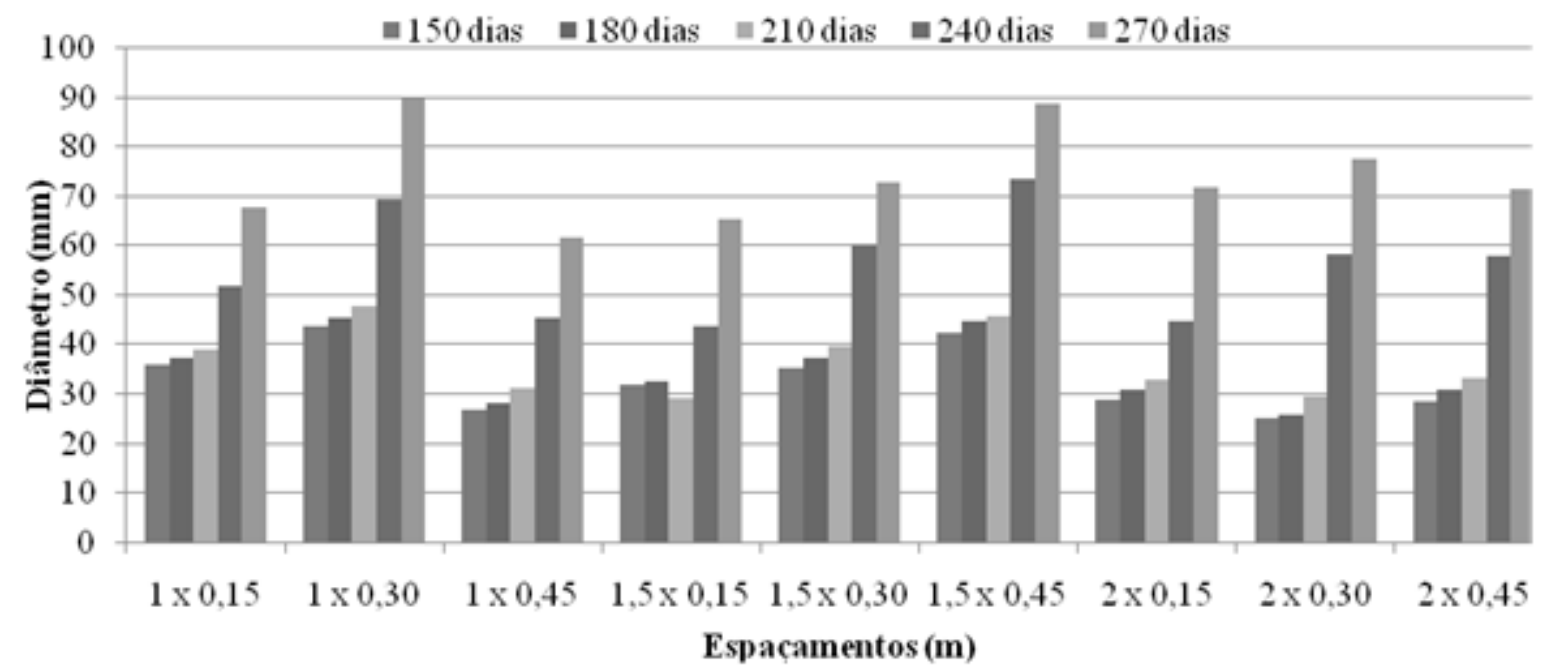

Figura 5. Diâmetro ao nível do solo, em milímetros, das plantas de capim vetiver, dos 150 aos 270 dias após o plantio em diferentes espaçamentos, Inconfidentes/MG. 


\section{Experimento 2 - Efeito do tipo de muda}

\section{Taxa de sobrevivência}

Quanto ao tipo de muda, pode-se observar di- ferença significativa (Tabela 4), onde o plantio de mudas em raízes nuas apresentou taxa de sobrevivência inferior $(86,85 \%)$ às mudas previamente preparadas em saquinhos de polietileno $(95,76 \%)$.

Tabela 4. Taxa de sobrevivência de mudas de vetiver em raízes nuas e produzidas em saquinhos de polietileno, Inconfidentes/MG.

\begin{tabular}{|c||c|}
\hline Tipo de Muda & Taxa de Sobrevivência (\%) \\
\hline \hline Mudas em Saquinhos de polietileno & $95,76 \mathrm{a}$ \\
\hline Mudas em "Raizes Nuas" & $86,85 \mathrm{~b}$ \\
\hline \hline CV & $7,30 \%$ \\
\hline
\end{tabular}

Médias seguidas pela mesma letra na coluna não diferem estatisticamente entre si, pelo teste de Tukey $(P<0,05)$.

Estes resultados estão relacionados ao fato das mudas em saquinhos de polietileno já estarem enraizadas e aclimatadas no momento do plantio, tendo, portanto, maiores condições e meios de sobreviver no campo quando comparadas as mudas em raízes nuas que não passam por este processo.

Pereira (2006) referenciou os benefícios de utilizarem-se mudas de vetiver enraizadas em saquinhos, dado a uma maior taxa de pegamento, apesar do aumento do custo de plantio.

Entretanto destacam-se os dois tipos de mudas apresentaram taxa de sobrevivência satisfatória, estando acima de $85 \%$.

\section{Altura das plantas}

As plantas de capim vetiver, provenientes de mudas em raízes nuas, inicialmente possuem desenvolvimento em altura inferior àquelas produzidas em saquinhos de polietileno, entretanto, com o passar do tempo, aos 240 dias após o plantio, o valor da altura destas mudas alcançam estatisticamente aquelas produzidas em saquinhos de polietileno, podendo inclusive ultrapassá-las (Tabela 5, Figura 6).

No período analisado, as plantas provenientes de mudas em raízes nuas destacaram-se com o maior crescimento no período, sendo $0,70 \mathrm{~m}$, não diferindo estatisticamente das mudas produzidas em saquinhos que obtiveram crescimento de 0,61m (Tabela 5).

Tabela 5. Altura, em metros, de plantas de capim vetiver, dos 150 aos 270 dias após o plantio das mudas em raízes nuas e produzidas em saquinhos de polietileno, Inconfidentes/MG.

\begin{tabular}{|c|c|c|c|c|c|c|}
\hline \multirow{2}{*}{$\begin{array}{c}\text { Espaçamen- } \\
\text { to }(\mathrm{m})\end{array}$} & \multicolumn{5}{|c|}{ Idade (dias) } & \multirow{2}{*}{$\begin{array}{c}\text { Crescimen- } \\
\text { to no Perío- } \\
\text { do }(\mathrm{m})\end{array}$} \\
\hline & 150 & 180 & 210 & 240 & 270 & \\
\hline Saquinhos & $0,57 \mathrm{a}$ & $0,71 \mathrm{a}$ & $0,83 \mathrm{a}$ & $1,09 \mathrm{a}$ & $1,18 \mathrm{a}$ & 0,61 a \\
\hline Raizes Nuas & $0,50 \mathrm{~b}$ & $0,62 a$ & $0,71 \mathrm{~b}$ & $1,00 \mathrm{a}$ & $1,20 \mathrm{a}$ & $0,70 a$ \\
\hline CV (\%) & 10,51 & 13,96 & 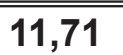 & 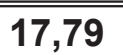 & 13,20 & 13,98 \\
\hline
\end{tabular}

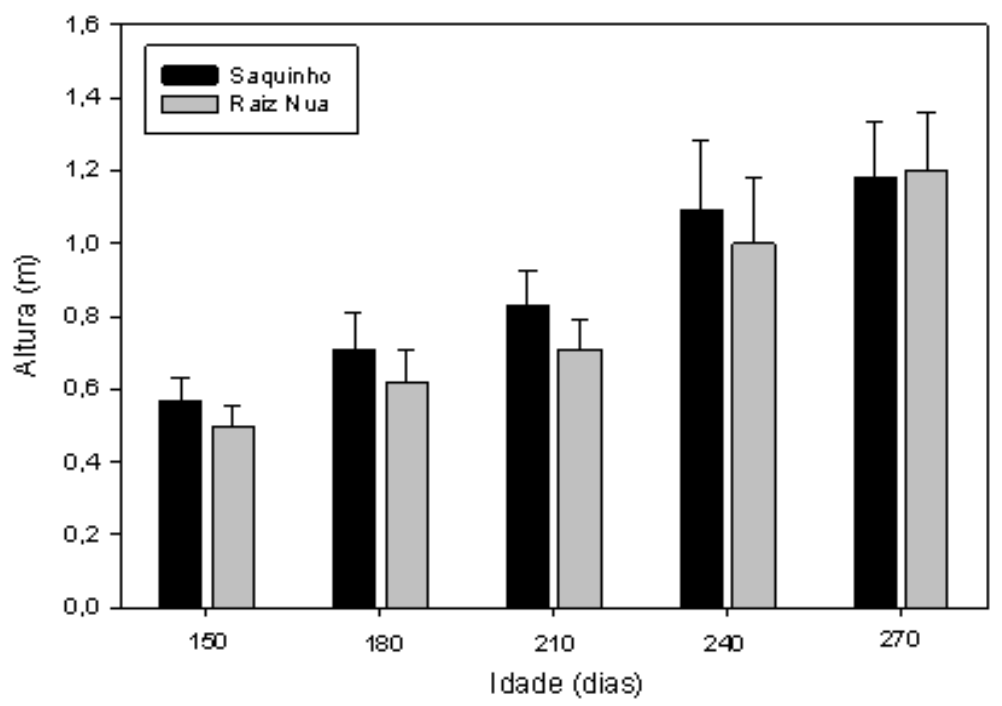


Avaliação da Sobrevivência e do Desenvolvimento de Mudas de Capim Vetiver (Vetiveria zizanioides) em Raízes Nuas e Produzidas em Saquinhos de Polietileno Plantadas em Diferentes Espaçamentos

Figura 6. Altura (m) e desvio padrão de plantas de capim vetiver, dos 150 aos 270 dias após o plantio das mudas em raízes nuas e produzidas em saquinhos de polietileno, Inconfidentes/MG.

\section{Diâmetro das plantas}

O diâmetro ao nível do solo em função do tipo de muda apresentou diferença estatística apenas aos 270 dias, conforme demonstra a tabela 6 . Observa-se que em todo o período analisado as mudas produzidas em saquinhos de polietileno apresentaram diâmetro ao nível do solo superior àquelas em raízes nuas. Estes resultados relacionam-se com os apresentados pela análise da taxa de sobrevivência das mudas, onde as mudas de vetiver produzidas em saquinhos de polietileno apresentam taxa de sobrevivência no campo superior àquelas plantadas diretamente no campo (raízes nuas).

Tabela 6. Diâmetro ao nível do solo, em milímetros, das plantas de capim vetiver, dos 150 aos 270 dias após o plantio das mudas em raízes nuas e produzidas em saquinhos de polietileno, Inconfidentes/MG.

\begin{tabular}{|c|c|c|c|c|c|c|}
\hline \multirow{2}{*}{$\begin{array}{c}\text { Espaçamen- } \\
\text { to }(\mathrm{m})\end{array}$} & \multicolumn{5}{|c|}{ Idade (dias) } & \multirow{2}{*}{$\begin{array}{c}\text { Crescimen- } \\
\text { to no Perío- } \\
\text { do }(\mathrm{m})\end{array}$} \\
\hline & 150 & 180 & 210 & 240 & 270 & \\
\hline \multirow{2}{*}{$\begin{array}{c}\text { Saquinhos } \\
\text { Raizes Nuas }\end{array}$} & $30,94 \mathrm{a}$ & $32,49 \mathrm{a}$ & $33,41 \mathrm{a}$ & $57,39 a$ & $79,40 \mathrm{a}$ & 48,46 a \\
\hline & $25,85 a$ & $27,11 \mathrm{a}$ & $28,66 \mathrm{a}$ & $46,50 a$ & $61,41 \mathrm{~b}$ & 35,56 a \\
\hline CV (\%) & 30,14 & 29,14 & 29,07 & 26,90 & 15,28 & 16,43 \\
\hline
\end{tabular}

Médias seguidas pela mesma letra na coluna não diferem estatisticamente entre si, pelo teste de Tukey $(P<0,05)$.

Destaca-se que aos 270 dias após o plantio, o diâmetro ao nível do solo das mudas de saquinhos de polietileno $(79,40 \mathrm{~mm})$ diferiu estatisticamente das mudas produzidas em raízes nuas $(61,41 \mathrm{~mm})$ fato este que demonstra um aumento em diâmetro ao nível do solo maior em mudas produzidas em saquinho de polietileno em relação às mudas de raízes nuas.

\section{CONCLUSÕES}

A taxa de sobrevivência, diâmetro ao nível do solo e altura das plantas de vetiver não são influenciados pelo espaçamento de plantio.

As plantas provenientes de mudas de vetiver produzidas em saquinhos de polietileno apresentam taxa de sobrevivência e diâmetro ao nível do solo superior àquelas plantadas diretamente no campo (raízes nuas).

Mudas produzidas em raízes nuas inicialmente apresentam menores valores de altura, entretanto após certo período de tempo estas mudas atingem valores similares ou maiores que os apresentados por mudas produzidas em saquinhos de polietileno.

\section{AGRADECIMENTOS}

À Fundação de Amparo à Pesquisa do Estado de Minas Gerais (FAPEMIG) pelo apoio financeiro ao projeto e bolsa de iniciação científica do quarto autor.

Ao IFSULDEMINAS - Campus Inconfidentes e seus servidores por todo o apoio de infra-estrutura e mão de obra.

\section{REFERÊNCIAS BIBLIOGRÁFICAS}

BERTONI, J.; LOMBARDI NETO, F. Conservação do solo. São Paulo, 2. ed., Ícone, 1990. 355p.
CAPUTI, J. Manejo e conservação do solo e da água em pastagens. In: SIMPÓSIO SOBRE ECOSSISTEMAS DE PASTAGENS, 3., 1997, Jaboticabal. Anais... Jaboticabal: UNESP-FCAV, 1997. p. 273-288.

CASTRO, P. T. da C.; Cobertura vegetal e indicadores microbiológicos de solo em talude regetado. Viçosa, MG, Universidade Federal de Viçosa 2007. 39p. Tese (Mestrado).

FERREIRA, D.F.; Análises estatísticas por meio do Sisvar para Windows versão 4.0. In: REUNIÃO ANUAL DA REGIÃO BRASILEIRA DA SOCIEDADE INTERNACIONAL DE BIOMETRIA, 45., 2000, São Carlos. Anais... São Carlos, SP: UFSCar, 2000. p.255-258.

MARTINHO, P.R.M. Contribuição para o estudo de técnicas de engenharia biofísica: grade de vegetação e grade de vegetação vesúvio, Évora, 2005. Acesso em 07 de ago. 2011. Online. Disponível em < http:// engenhariaverde.planetaclix.pt/pdf/tfc.pdf $>$

MOREIRA, P.R. Manejo do solo e recomposição da vegetação com vistas a recuperação de áreas degradadas pela extração de bauxita, Poços de Caldas, MG. 2004. 155f. Tese (Doutorado em Ciências Biológicas) - Instituto de Biociências da Universidade Estadual Paulista "Julio de Mesquita Filho", Rio Claro, SP.

PEREIRA, A.R. Uso do vetiver na estabilização de taludes e encostas. Boletim técnico, Deflor Bioengenharia, ano $1 \mathrm{n} .03$, Set., 2006.

TRUONG, P.N. HART, B. Sistema Vetiver para tratamento de águas residuais. Boletim Técnico No. 2001 / 2. Rede Vetiver para as Orlas do Pacifico. Royal Projetos Admistrativos de Desenvolvimento, Bangkok, Tailândia., 2001. 